\title{
Attractions of delay: Using deliberative engagement to investigate the political and strategic impacts of greenhouse gas removal technologies
}

\author{
Duncan McLaren ${ }^{\mathrm{a}^{*}}$, Rebecca Willis ${ }^{\mathrm{a}}$, Bron Szerszynski ${ }^{\mathrm{b}}$, David Tyfield ${ }^{\mathrm{a}}$ and Nils Markusson ${ }^{\mathrm{a}}$ \\ * Corresponding author: email d.mclaren@lancaster.ac.uk; Lancaster Environment Centre, Lancaster \\ University, Library Avenue, Lancaster LA1 4YQ \\ a Lancaster Environment Centre, Lancaster University, UK \\ ${ }^{\mathrm{b}}$ Department of Sociology, Lancaster University, UK
}

\begin{abstract}
Concerns have been raised that a focus on greenhouse gas removals (GGR) in climate models, scientific literature and other media might deter measures to mitigate climate change through reduction of emissions at source - the phenomenon of 'mitigation deterrence'. Given the urgent need for climate action, any delay in emissions reduction would be worrying. We convened nine deliberative workshops to expose stakeholders to futures scenarios involving mitigation deterrence. The workshops examined ways in which deterrence might arise, and how it could be minimised. The deliberation exposed social and cultural interactions that might otherwise remain hidden. The paper describes narratives and ideas discussed in the workshops regarding political and economic mechanisms through which mitigation deterrence might occur, the plausibility of such pathways, and measures recommended to reduce the risk of such occurrence. Mitigation deterrence is interpreted as an important example of the 'attraction of delay' in a setting in which there are many incentives for procrastination. While our stakeholders accepted the historic persistence of delay in mitigation, some struggled to accept that similar processes, involving GGRs, may be happening now. The paper therefore also reviews the claims made by participants about mitigation deterrence, identifying discursive strategies that advocates of carbon removal might deploy to deflect concerns about mitigation deterrence. We conclude that the problem of mitigation deterrence is significant, needs to be recognised in climate policy, and its mechanisms better understood. Based on stakeholder proposals we suggest ways of governing GGR which would maximise both GGR and carbon reduction through other means.
\end{abstract}

\section{Highlights}

- Greenhouse gas removal discourses exemplify how technological promises enable prevarication through their enrolment in scientific, cultural, economic and political processes

- Many stakeholders share concerns that mitigation deterrence is arising from exaggerated expectations regarding future greenhouse gas removal technologies

- Novel futures scenario deliberations effectively expose and highlight cultural and political dimensions and risks of possible climate policy pathways

- Policy recommendations include separate targets for removals and emissions reductions, and interventions to counteract the power of incumbent vested interests

- Recognizing the risks requires a shift of deliberative register to one permitting reflexive consideration of cultural, political and economic effects 


\section{Introduction}

Proposals to remove greenhouse gases from the atmosphere - referred to as greenhouse gas removal (GGR) or carbon removal - are increasingly important to climate policy. Many analyses suggest that a goal of limiting warming to $1.5^{\circ} \mathrm{C}$ cannot be achieved without substantial GGR (Luderer et al., 2018; Rogelj et al., 2018). Yet others highlight the risks of relying on unproven or uncertain technologies, particularly when promises of such technologies might deter or delay action to reduce emissions (Anderson and Peters, 2016; Fuss et al., 2014; McLaren, 2016). This latter problem has been termed 'mitigation deterrence' (Markusson et al., 2018; McLaren, 2016). It is difficult to establish the extent to which promises or expectations of carbon removal, featured in models, media and corporate finance, might deter emissions reduction in practice, although McLaren (2020) estimates that in the worst case, the effects could add up to a further $1.4^{\circ} \mathrm{C}$ warming on top of a $1.5^{\circ} \mathrm{C}$ pathway. Given the need for accelerated, far-reaching climate action, any delay resulting from carbon removal promises would be worrying.

Previous scholarship has identified GGR discourses as having potential to sustain climate procrastination, and has mapped out ways in which such emerging technologies might be mobilised as spatio-temporal or socio-ecological fixes for crises of capitalism. Examining reasons for failure to 'bend the emissions curve', Stoddard et al. (2021) emphasize the role of hegemonic economic interests with techno-economic mindsets and ideologies of control. In this context, GGR promises are vulnerable to being misused to delay reductions in fossil fuel use. Lamb et al. (2020) map out multiple discourses underpinning rolling inaction, or delay, including a 'technological optimism' category into which the potentially exaggerated promises of GGR fit perfectly. The prevalence of 'over-optimistic assumptions' or 'unreliable expectations' of the feasibility of GGR has been highlighted in recent reviews of the GGR included in countries' low-emission development plans (Thoni et al., 2020) and of particular GGR techniques (Waller et al., 2020) ${ }^{1}$.

Other scholars have suggested that GGR innovations and promises might be understood as prospective spatio-temporal fixes - following Harvey (2003) and Jessop (2006) - in which not only engineered technologies and infrastructures but also managed landscapes and biophysical processes are enrolled as responses to capitalist crises (Sapinski, 2016; Carton, 2019; Ekers and Prudham, 2017). In previous and parallel work (Markusson et al., 2018; Markusson et al., forthcoming), we locate such technological promises as a key element in the cultural political economy of climate change, in which innovation narratives and imaginaries are simultaneously a product of, and a means to sustain hegemonic economic power, via concepts and processes particularly including commodification (Jessop, 2009; Sum and Jessop, 2013). Concerns regarding the ways in which commodification and marketization of climate change reshape the science and technologies of mitigation, entrenching institutions and procedures that resist transformative change, are longstanding (Lohmann, 2005; Newell and Paterson, 2010). More recently scholars have highlighted how treating carbon as fungible (and as an isolated metric) has undesirable consequences, generating both a set of false equivalences (Carton et al., 2021) and a set of political, and associated epistemic presumptions (Moreno et al., 2015) which tend to separate considerations of climate policy from those of power. Our work adds to this literature in that it applies the concept of mitigation deterrence to the arena of emerging policy and practice for GGR, so as to explore in detail the mechanisms and impacts of both spatial and temporal dimensions of inappropriate carbon fungibility and re-emplace climate concerns and responses in the context of the cultural political economy.

\footnotetext{
${ }^{1}$ Waller et al consider bioenergy with carbon capture and storage (BECCS) and afforestation.
} 
In this paper we report findings from deliberative workshops regarding whether and in what ways stakeholders in carbon removal hold concerns about mitigation deterrence, the mechanisms which they see as plausible sources of delay, and the measures that they suggest might be taken to minimise negative impacts. Our findings cast new light on the dynamics of delay, the limitations and pitfalls of offsetting and the commodification of carbon, and on the politics of technological and spatio-temporal fixes. We use 'delay' as the primary term in preference to more normatively loaded concepts such as prevarication or procrastination because the problem is not necessarily a product of deliberate intervention, but can also emerge systemically.

In climate science and policy, GGR is understood to serve two purposes. First, to help achieve 'net zero' emissions targets by balancing any residual or 'recalcitrant' emissions. Second, to compensate for any overshoot in greenhouse gas emissions over time, by subsequently drawing down carbon from the atmosphere. There would be little reason to worry about deterrence in either case if the amounts involved could be objectively defined and fixed in advance. Yet both 'recalcitrant' emissions and 'unavoidable' overshoot are matters of political debate and scientific uncertainty. Climate scientists, policymakers, publics and commercial interests interact to shape definitions and expectations. Proposals and promises of GGR technologies also affect expectations and definitions of recalcitrance and overshoot. Put simply, the more plausible or attractive the GGR offer, the weaker the apparent carbon budget constraint, and the greater the incentive to broaden the definition of recalcitrant emissions, and to accept larger overshoot.

Previous research has reported public opinions and views regarding carbon dioxide removal (CDR) technologies. Concerns about mitigation deterrence have been shown to detract from public support for various forms of carbon removal in both the UK and US (Bellamy et al., 2019; Cox et al., 2020). Our deliberative stakeholder workshops explored the social and cultural interactions between carbon removal and emissions reduction promises and practices, involving a diverse range of stakeholders and experts (rather than publics), focusing on whether and how mitigation deterrence might manifest in various political scenarios, and how it might be minimised.

The paper continues with a description of the theoretical orientation and methodology of the project (section 2). After that, we report (section 3.1) participants' views on the nature and plausibility of scenarios with mechanisms of deterrence, and the political and economic drivers that might favour deterrence and delay. Subsequently (section 3.2), we review claims made about mitigation deterrence to identify discursive strategies deployed by advocates of GGR. On the surface, such strategies deflect concerns about mitigation deterrence, but we argue that at a deeper level they illustrate the pervasiveness of the problem. The paper then outlines (section 3.3) the measures that participants recommended to promote GGR whilst avoiding or minimising mitigation deterrence.

Section 4 discusses these findings, and in conclusion, we suggest that mitigation deterrence caused by GGR promises should be understood as just one example of an 'attraction of delay' within a cultural and political setting that provides many incentives for procrastination. We highlight possible measures to minimise deterrence, stimulate the delivery of GGR, and reduce resistance to mitigation more generally. 


\section{Purpose and methods}

We convened nine deliberative workshops in 2018 and 2019 in which we exposed climate/GGR experts and stakeholders ${ }^{2}$ to speculative futures scenarios involving mitigation deterrence. Our aim was to identify and examine ways in which it might arise and to stimulate responses as to how to minimise it in practice. Five face-to-face workshops were convened in London; and four online using Zoom, with a range of international participants. Each workshop involved between six and nine stakeholders for an aggregate total of 66 participants.

Participants were recruited using a snowball method amongst academics, experts and other stakeholders identified through the literature, conference participation, and media commentary. Particular efforts were made to include relevant policy makers, environmental NGOs, labour unions and climate journalists. More generic and future-oriented public interests were included by involving students taking climate politics and environmental technology courses. ${ }^{3}$ While the participants were broadly drawn from social elite groups, by making the workshop groups diverse in initial opinions and presumptions, we sought to enable debate and reflexivity. In total, the workshops involved 21 academics, 15 participants from industry or consultancy, 11 from NGOs or unions, 5 from policymaking bodies, 4 from media and 10 students. Only 16 of the 66 participants were women. Although this reflects the GGR field in general, we sought to remain alert to the gender imbalance in these discussions.

Each workshop took the same basic structure, following a detailed facilitation guide prepared in advance (see supplementary material). The workshops were structured around discussion of scenarios for deployment of GGRs developed by the research team drawing on the GGR literature and expert interviews ( $n=17$ ) regarding the plausible development, scale and promises of GGR technologies. Each scenario was designed to describe a plausible future (Wilkinson et al., 2013) to 2050 in which GGR (either generically, or in the form of one of four specific technologies) offered significant promise, but also undermined progress on emissions reduction. The four technologies considered in detail were bioenergy with carbon capture and storage, direct air capture, soil carbon restoration, and enhanced weathering. The scenario narratives offered a framework to elicit responses and collective discussion about the extent, nature, mechanisms and drivers of mitigation deterrence effects arising in consideration of GGR, both testing and permitting the stakeholders involved to interrogate and challenge our existing hypotheses (illustrated in the scenarios).

The workshops, scenarios and facilitation approaches were all designed to enable participants to adopt a situated, strategic ${ }^{4}$ perspective as part of a collective group, rather than that of a singular, isolated, external 'objective' observer (Tyfield, 2020; Flyvbjerg et al., 2012) and thus developing and adapting their views through an iterative and reflexive form of 'public reasoning' (Burchardt, 2014). In practice this involved using the scenarios to facilitate and stimulate situated discussion and responses and doing so iteratively across three temporal horizons, as described later in this section. This design approach reflects a perspective on technological promises grounded in cultural political economy (CPE) (Markusson et al., 2018; McLaren and Markusson, 2020; Sum and Jessop, 2013). CPE

\footnotetext{
${ }^{2}$ Stakeholders are here understood as those with knowledge about or an interest in GGR, including those who may be affected by promises and projects, as well as those with power to affect such developments. While 'stakeholder' terminology and practices can be depoliticising (Swyngedouw 2004), our workshops explicitly politicised the issues at hand through the use of politically contrasting scenarios.

${ }^{3}$ Student participants were offered a small honorarium. For other participants, the same sum was donated to a charity of their choice.

${ }^{4}$ Strategic' is here used the sense of having regard to wider longer-term or overall aims and objectives and the means to achieve them, as opposed to a narrow focus on immediate or limited aims.
} 
combines the insights of social constructivism (the 'cultural') with a material political economy, identifying systemic and emergent effects. This 'CPE register' - in which hegemonic economic power, promises and imaginaries of technological fixes, and market ideologies of commodification and trading are critical considerations - contrasts with a conventional and dominant 'rationalist register' in discourse which emphasizes objectivity and reason, for instance by privileging the aggregate effects of individual decisions over emergent cultural effects (Markusson et al., 2018). The rationalist register reflects a family of well-established 'civic epistemologies' (Jasanoff, 2007) prevalent in the western (neo)liberal world - including the countries from which our participants were mainly drawn - which centre calculative, consequentialist and utilitarian analysis and universal principles (Nardin, 2015). The move to a CPE register involves not only reframing the issue at stake, from techno-economic feasibility to 'responsible development' (Waller et al., 2020), but also a shift in subjectivity.

For each workshop, scenarios considered the same technology (or GGR generically) under two imagined political futures, selected from a matrix of four alternatives based loosely on grid/group theory (Douglas, 1970). Alongside a 'business as usual' future in which global politics remains much as at present (weakly neoliberal, and at best 'muddling through' in face of populist and authoritarian challenges), we postulated three diverse and stylized futures - one each based on strong publics (more egalitarian and progressive), strong leaders (an authoritarian turn) and strong markets (a revived neo-liberalism) (see Table 1 and supplementary material). In each workshop one scenario was described in detail in three temporal steps, with a sequence that ran through GGR promises (in 2020), disappointing results (in 2030) and finally some clarity as to how and why GGR had deterred emissions reduction (in 2050). These temporal steps enabled participants to collectively revisit their responses to the emanations of mitigation deterrence described. The second scenario was presented only in summary (as a retrospective from 2050), to provide contrasting political stimulus for facilitated discussion. The scenarios were consistently paired: 'business as usual' was contrasted with 'progressive politics'; or 'revived neoliberalism' with the 'authoritarian turn' and across the set of workshops both pairs were applied to each of the four technologies. The arrangement of 'diagonally opposite' pairs was designed to leave both axes of the grid/group matrix applicable in each workshop.

The workshops were recorded, transcribed, anonymised and analysed qualitatively using Atlas.ti. Following the workshops, the team constructed a coding guide, and each transcript was coded by two separate readers. Conflicting codings were resolved by the lead reader, who read and coded all nine transcripts. The purpose of the analysis was to identify and follow ideas and narratives as they evolved through each discussion, rather than focusing on which individual said what. Nonetheless such analysis of deliberation can offer insights into individual as well as collective responses to the ideas and narratives under discussion (Burchardt, 2013). In other words, we sought to work at the interface between ideas and actors, understood as a space where technologies and regimes are rhetorically constructed and reconstructed. We recognise that such engagements also construct and reconstruct forms of subjectivity and collectivity amongst participants (Chilvers and Kearnes, 2019; Bellamy and Lezaun, 2017). The analysis that follows is therefore both interpretive and evaluative, alert both to how perspectives can be constructed in the discussions and to our own positionality in the discussions. The quotations used in the following text are identified by an Atlas code which refers to the transcript and specific marked text. ${ }^{5}$

\footnotetext{
${ }^{5}$ For readers interested in how the cited quotes represent the richer material, see supplementary material.
} 
Table 1: Key features of the workshop scenarios

\begin{tabular}{|c|c|c|c|c|}
\hline Scenario & Politics & $\begin{array}{l}\text { GGR } \\
\text { technique }\end{array}$ & Key features & $\begin{array}{l}\text { Workshop } \\
\text { formats }\end{array}$ \\
\hline 1.1 & $\begin{array}{l}\text { Business as } \\
\text { usual }\end{array}$ & Generic & $\begin{array}{l}\text { Extensive carbon markets promised but dogged by } \\
\text { political delay, carbon fraud prevalent in offsetting } \\
\text { markets, GGR deployed only in profitable niches, } \\
\text { predominantly for carbon utilisation rather than } \\
\text { removal. }\end{array}$ & $\begin{array}{l}\text { 3-step } \\
\text { F2F \& Virtual }\end{array}$ \\
\hline 1.2 & $\begin{array}{l}\text { Business as } \\
\text { usual }\end{array}$ & BECCS & $\begin{array}{l}\text { Innovative methods promise BECCS with limited } \\
\text { land-use conflicts. Technical, political and } \\
\text { commercial factors limit adoption, with carbon } \\
\text { markets favouring biomass cofiring without CCS. } \\
\text { BECCS promises continue to be mobilised by fossil } \\
\text { fuel and power companies to sweat assets, and } \\
\text { actual deployment is limited to sites where } \\
\text { enhanced oil recovery is possible. }\end{array}$ & $\begin{array}{l}\text { 3-step } \\
\text { F2F \& Virtual }\end{array}$ \\
\hline 1.3 & $\begin{array}{l}\text { Business as } \\
\text { usual }\end{array}$ & $\begin{array}{l}\text { Soil Carbon } \\
\text { Storage }\end{array}$ & $\begin{array}{l}\text { Soil carbon promises adopted internationally, } \\
\text { backed by carbon credits and blockchain } \\
\text { technologies. Removals delayed by conflicts over } \\
\text { agricultural support regimes. Benefits prove more } \\
\text { limited than promised, and are offset by more } \\
\text { livestock production. Soil carbon stores leak in } \\
\text { warming climate. Fraud proves widespread in many } \\
\text { support regimes. }\end{array}$ & $\begin{array}{l}\text { 3-step } \\
\text { F2F }\end{array}$ \\
\hline 2.1 & $\begin{array}{l}\text { Progressive / } \\
\text { egalitarian }\end{array}$ & Generic & $\begin{array}{l}\text { Green New Deal promised to lead transition. Public } \\
\text { opposition to tech fixes (nuclear and CCS) slows } \\
\text { mitigation, and political conflicts over land-grabbing } \\
\text { slows GGR, leading to emergence of justice-based } \\
\text { movements calling for carbon removal instead of } \\
\text { mitigation. }\end{array}$ & $\begin{array}{l}\text { 3-step } \\
\text { F2F \& Virtual }\end{array}$ \\
\hline 2.2 & $\begin{array}{l}\text { Progressive / } \\
\text { egalitarian }\end{array}$ & BECCS & $\begin{array}{l}\text { Economic and financial bubbles and crashes of the } \\
2020 \text { s sideline climate policy. Progressive leaders in } \\
2030 \text { s promise redistribution, job creation, fair } \\
\text { climate action and respect for human rights. Major } \\
\text { economies reject nuclear power, making carbon } \\
\text { budgets hard to balance. BECCS is endorsed at global } \\
\text { summits in } 2032 \text { and } 2037 \text { but low investment } \\
\text { confidence combined with activist opposition to } \\
\text { biomass landgrabs, and carbon stores undermines } \\
\text { progress. }\end{array}$ & $\begin{array}{l}\text { Retrospective } \\
\text { F2F \& Virtual }\end{array}$ \\
\hline 2.3 & $\begin{array}{l}\text { Progressive / } \\
\text { egalitarian }\end{array}$ & $\begin{array}{l}\text { Soil Carbon } \\
\text { Storage }\end{array}$ & $\begin{array}{l}\text { Economic and financial crashes lead to elections of } \\
\text { progressive leaders promising redistribution, job } \\
\text { creation and respect for human rights. In climate } \\
\text { policy, soil carbon removal and afforestation are } \\
\text { preferred to capital-intensive measures (from public } \\
\text { transport to DAC). Nuclear power and CCS are } \\
\text { rejected to please progressive voters. Soil and forest } \\
\text { removals are undermined both by leakage and by } \\
\text { emission rebounds, as the 'Soil-cialist movement' } \\
\text { demands equal carbon rights for the poor. }\end{array}$ & $\begin{array}{l}\text { Retrospective } \\
\text { F2F }\end{array}$ \\
\hline 3.1 & $\begin{array}{l}\text { Authoritarian } \\
\text { / populist }\end{array}$ & Generic & $\begin{array}{l}\text { Chinese led 'climate emergency' plans for carbon } \\
\text { removals and population relocation; indiscriminate } \\
\text { deployment of GGR undermines performance and } \\
\text { empowers backlash; extractive \& fossil }\end{array}$ & $\begin{array}{l}\text { 3-step } \\
\text { F2F }\end{array}$ \\
\hline
\end{tabular}




\begin{tabular}{|c|c|c|c|c|}
\hline & & & $\begin{array}{l}\text { corporate/state interests maintain substantial power } \\
\text { and delay emissions reductions. }\end{array}$ & \\
\hline 3.2 & $\begin{array}{l}\text { Authoritarian } \\
\text { / populist }\end{array}$ & $\begin{array}{l}\text { Direct Air } \\
\text { Capture } \\
\text { (DAC) }\end{array}$ & $\begin{array}{l}\text { China and US compete to develop DAC technologies } \\
\text { in response to growing climate impacts. US focuses } \\
\text { on synthetic fuel market, not storage. DAC } \\
\text { deployment is limited, and also diverted into } \\
\text { international offset schemes. Authoritarian regimes } \\
\text { restrict some domestic emissions, but continue to } \\
\text { enable fossil extractivism. Carbon intensity of energy } \\
\text { production remains relatively high, undermining net } \\
\text { effectiveness of energy-intensive DAC. }\end{array}$ & $\begin{array}{l}\text { 3-step } \\
\text { Virtual }\end{array}$ \\
\hline 3.3 & $\begin{array}{l}\text { Authoritarian } \\
\text { / populist }\end{array}$ & $\begin{array}{l}\text { Enhanced } \\
\text { weathering }\end{array}$ & $\begin{array}{l}\text { Innovations in grinding technology generate } \\
\text { promises of enhanced weathering carbon removal, } \\
\text { adopted by various populist leaders for diverse } \\
\text { reasons (mining interests, agricultural co-benefits, } \\
\text { even as anti-colonial rhetoric). Effects are } \\
\text { undermined by land-use rebounds, and } \\
\text { unexpectedly rapid saturation of carbon storage. But } \\
\text { political strength of mining and other interests locks } \\
\text { in policy despite shortcomings, while growing } \\
\text { pressures for climate migration maintain populist } \\
\text { anti-immigration regimes. }\end{array}$ & $\begin{array}{l}\text { 3-step } \\
\text { Virtual }\end{array}$ \\
\hline 4.1 & $\begin{array}{l}\text { Neoliberalism } \\
2.0\end{array}$ & Generic & $\begin{array}{l}\text { Cities and corporations promote market-based } \\
\text { climate pact; boom in financial instruments for } \\
\text { 'climate hedging'; carbon removal technology gets } \\
\text { locked into carbon utilisation applications, while } \\
\text { nature-based offsets become saturated and leaky. }\end{array}$ & $\begin{array}{l}\text { 3-step } \\
\text { F2F }\end{array}$ \\
\hline 4.2 & $\begin{array}{l}\text { Neoliberalism } \\
2.0\end{array}$ & DAC & $\begin{array}{l}\text { EU-China carbon-market deal triggers neoliberal } \\
\text { climate policy with a focus on carbon removal by } \\
\text { innovative direct air capture. Markets deliver carbon } \\
\text { capture, but not storage, with high rates of diversion } \\
\text { of carbon to utilisation, and much offsetting of } \\
\text { continued fossil fuel use. Slow development of } \\
\text { carbon storage and transmission facilities limits } \\
\text { overall removal rates. }\end{array}$ & $\begin{array}{l}\text { Retrospective } \\
\text { Virtual }\end{array}$ \\
\hline 4.3 & $\begin{array}{l}\text { Neoliberalism } \\
2.0\end{array}$ & EW & $\begin{array}{l}\text { Resistance from financial interests to closing borders } \\
\text { and rising tariffs triggers a trade boom and global } \\
\text { growth (slowing emissions reduction). Revived } \\
\text { neoliberal climate efforts establish global carbon } \\
\text { markets - including carbon removal. Volatility in } \\
\text { carbon markets generates a dash for enhanced } \\
\text { weathering. Promises of future removals mask short- } \\
\text { term risks which burst the carbon market bubble. }\end{array}$ & $\begin{array}{l}\text { Retrospective } \\
\text { Virtual }\end{array}$ \\
\hline
\end{tabular}

\section{Deliberating about mitigation deterrence}

In this section we outline the findings from the workshops, in three stages. First, we investigate the extent and nature of concerns about mitigation deterrence and its possible drivers and mechanisms. Second, we explore the arguments raised to suggest that mitigation deterrence might not occur. Finally, we summarise the interventions that were suggested to maximise greenhouse gas removals, while not impairing other efforts to reduce carbon emissions. 


\subsection{Drivers and mechanisms of deterrence}

Across the workshops, participants expressed common understandings of the ways in which mitigation deterrence could occur. The use of scenarios, and particularly the elaboration of 'social imaginaries' - shared understandings of how the world works (Groves, 2014; Taylor, 2003; Jasanoff, 2015) helped participants to explore the issue.

\section{Social imaginaries and attractions of delay}

Participants mapped out a broad social imaginary in which social change is resisted, identifying (what we call) 'attractions of delay': reasons why key actors, including publics, businesses, and politicians, might want to delay action on climate. Participants emphasised how high-carbon industries are economically locked-in and structurally powerful, and strongly motivated to find any possible loopholes (or even to behave fraudulently) to exploit otherwise potentially stranded assets.

As one participant said, "the allure of negative emissions" is that "it delays action to the future ... that temptation will still be there to think we'll still be able to recover in the future by relying on negative emissions." (24:38). Another emphasized that: "a system where we can continue consuming is going to be preferred by the public, by the government, by industry. That's why that potential problem with GGR, as we've been saying, [is that] it allows for continued emissions" (29:30). And no-one is prepared to bear the costs of delivery. As one participant explained, industry representatives might claim "It's down to the government to do all this", but "the government's saying 'no we haven't got any money. It's down to the industry'” (29:32).

In another group it was suggested that mitigation deterrence happens "largely because we're locked into existing structures. ... we can't just leave it up to markets, we can't just leave it up to the invisible hand of innovation to come up with something better. We need to actually actively close down these systems" (22:103). In other words, without efforts to close down fossil industries they will inevitably promise GGR to enable continued extraction and use of fossil fuels. Moreover, business is expected to avoid material action as far as possible, by manipulating and gaming carbon markets and offsetting systems: "The thing with any system you put together ... Barclays Bank have some skyscraper in Canary Wharf full of people just looking for loopholes" (29:73).

The discussions often implicated modelling as part of the ingrained structures of policy delay. Integrated assessment modelling puts forward cost-optimising pathways to climate targets, involving large amounts of GGR. One participant saw this as an example of a common tendency "towards spreadsheet bias ... the tool says, the rationality provided by Microsoft Excel says, that this is true" (25:60). The academic literature has also identified this problem, but so far, only limited efforts have been made to correct for it (Fuss et al., 2014; Beck and Mahony, 2018; Peters and Geden, 2017; Rogelj et al., 2019).

\section{Exaggeration and the power of promises}

The scenarios illuminated the power of promises. Many participants portrayed promises as powerful, regardless of material viability, and warned against the incentives for vested interests of greenwashing, or making fraudulent promises.

One put their view simply: "It's all spin. The technologies are not going to be realised" (25:7). Many suggested that mitigation deterrence would arise if GGR were seen as a 'silver bullet'. The alternative was to seek "a solution that isn't the kind of perfectly cost-optimal spreadsheet or model but, in fact, is a real world muddling through" (25:71). Experts in particular GGRs tended to argue that misleading promises were not produced by them, but by opponents of their technologies: "It 
doesn't matter what we tell ... there will always be people to say you're trying to present this as the entire solution ..." (21:55).

Other participants worried more about exaggeration by proponents of GGR or related interests. As one said: "[they highlight] the lowest cost estimate which you could feasibly do ... you've seen that already with direct air capture" (22:9). Likewise, some noted more unequivocally deliberate efforts to mislead, especially by corporate interests, citing past examples of "chicanery" in electricity trading (26:17) and fraudulent behaviour in poorly verified offsetting (22:23). Similar fears were expressed about "greenwashing" in advocacy for "carbon capture and utilisation ... instead of actually storing $\left[\mathrm{CO}_{2}\right]^{\prime \prime}$ (24:22). Some argued that a focus on GGR could allow politicians and vested interests to defend slow mitigation: "I think the ambiguity is also part of the attraction" (23:82). Another explained, "if we use these [GGR] technologies ... we'll be able to use more coal and gas. It will ... be a way [for] ... the fossil fuel industry to keep their grip on the economies of the world" (24:30).

\section{Rational substitution and its failings}

The workshop discussions also confirmed ways in which promises - whether well-meaning or fraudulent - could interact with apparently rational economic and temporal substitution effects to create risks of deterrence outcomes.

Some participants - typically early in our workshops - began with appeals to rational economics, arguing that allowing GGR removals to trade in well-regulated carbon markets is a straightforward way of funding their development and deployment. But for many participants, carbon markets and the implied offsetting mechanisms involved are themselves the problem, and adding GGR to them would make for more prevarication and delay. As one put it: "essentially you're going to eat up the cheaper [GGR] reductions first, and leave yourself with a harder problem at the end of the day, and emissions will continue to increase" (26:5). As discussions progressed, we heard widespread deep scepticism about carbon markets. For instance: "a market is to make money for the traders; it's not to reduce emissions" (25:15). Some participants therefore argued for measures that could establish a firm carbon price without allowing trading and offsetting. But carbon pricing mechanisms alone were not seen as a solution, given the incumbent political and economic interests involved: "at the moment, what we're doing is leaving it up to markets ... the whole GGR discourse just seems [to accept] that you create a carbon price and that will just fix everything and then you can just sit back. It's clear that in terms of incumbency that approach doesn't work" (22:105).

Critiques of 'rational' substitution extended to international offsetting, and temporal transfers. For example: "[the] UK can say we're going to do a bit in this space but actually we're going to carry on high carbon lifestyles because in addition we can fund South Sudan to do what they need to do anyway" (23:7). Such international offsetting via GGR acts as an unfair 'first mover advantage', which poorer countries cannot imitate. We heard similar concerns about the temporal dimension of using future GGR to compensate for near-term emissions. As one participant stressed: "what makes climate change such a particularly wicked problem for dealing with is that it is long-term and multigenerational. It's very easy for people to give the semblance of taking action and then take their foot off the accelerator and coast for a bit before the next crisis hits" (23:135).

\section{Mechanisms vary with GGR techniques and politics}

Exploring different technologies and political scenarios helped highlight some mechanisms, because of differential susceptibility. GGR techniques not requiring large up-front capital investment, or where outcomes would be more difficult to monitor, were considered more susceptible to exaggerated promises. By contrast, those with high capital costs were seen as vulnerable to diversion to carbon utilisation in enhanced oil recovery or synthetic fuels. 
We saw particular vulnerabilities to market-based offsetting mechanisms in the neo-liberal and business-as-usual political settings, while authoritarianism was anticipated to increase vulnerability by undermining international cooperation, and disrupting the institutions and mechanisms for delivery and monitoring of climate action. In this vein, several participants questioned why populist authoritarian leaders would even make promises about GGR: "does Trump even need an excuse not to do anything about climate change?" (22:3). But participants also recognised the vulnerability of a 'post-truth' context to exaggerated promises, and continued claims that promises were being delivered, regardless of evidence: "I find this horribly plausible ... regimes that do this stuff are [asking] ... not 'can we balance the numbers', ... [but] 'have we got a story that we can tell that can buy off our supporters on this particular subject?' (22:32). Trump's more recent endorsement of the Trillion Tree goal, despite its huge limitations, would seem to confirm such fears.

This section has outlined a range of mechanisms whereby deterrence might arise in the interplay of interests, promise and exaggeration. The discussions described a world with multiple incentives for delay based in promises, expectations and shared social imaginaries. Next we turn to some of the counter-arguments offered, and a series of common claims made about why mitigation deterrence might not be problematic.

\subsection{Reasons to be cheerful?}

Some participants were sceptical about the idea of mitigation deterrence, especially early in the sessions. There were three broad reactions to the idea of mitigation deterrence, typically advanced as reasons why it may not occur - or why, even if it were to occur, it might not be a problem. First, there was an argument that both GGR and emissions reduction are needed, and therefore both will happen. Second, some claimed GGRs were too expensive, or too limited in other ways, to materially undermine emissions reduction action. Third, several participants argued that delays in mitigation could not continue to be justified, and that 'someone would have done something' before the situation got as bad as depicted in our scenarios. These three 'rationalist' arguments can, however, also be understood as expressions of deterrence effects. In the workshops, we saw groups move beyond these claims and discuss ways to maximise GGR while simultaneously reducing emissions.

\section{'Both emissions reduction and GGR are required'}

A claim that 'everything is needed' was typically made on the basis that a $1.5^{\circ} \mathrm{C}$ limit on warming is now only deliverable with the aid of GGR, as an offset for recalcitrant emissions and/or as a tool to compensate for an overshoot in atmospheric $\mathrm{CO}_{2}$. "If you want $1.5^{\circ}$ you've got to throw everything at it, this and everything else" (29:35).

In making such claims, some participants simply rejected the possibility of mitigation deterrence: "Obviously we will need negative emission technologies to put carbon somewhere else, to manage carbon. ... the discussion about 'this is going to slow down [mitigation]' ... I don't buy that." (21:59). Others acknowledged the risk, but deemed it irrational: "some people will see [BECCS] as a get out of jail card but I think that will be incredibly misguided. Both because deployment is so far off but also it's kind of... it's only ever going to be an insurance mechanism" (19:31). Such rejections were typically framed as assertions or declarations of belief, and other participants often pushed back, with comments like: "this worry that there will be mitigation deterrence is a very real issue" (26:21).

Some participants deemed a risk of mitigation deterrence acceptable given the need for GGR: "we don't have to slow down because we're worried about this mitigation replacement thing. Let's get ahead and do some of this stuff and if it turns out there is a lot of replacement then we've got time 
to figure out financial and legal ways of restraining that" (26:73). A minority even advocated actively positioning GGR as a tool to allow continued fossil extraction (effectively encouraging substitution). Such views were justified by arguments that political will is inadequate to prevent overshoot, and thus GGR essential; and that such a framing could reduce opposition to climate action: "You can reframe GGR in ways to make it sound like something new rather than the same old, same old, global warming argument" (28:16).

Participants also often cited 'recalcitrance' - the idea that certain emissions cannot be practically eliminated. As one participant argued: “... actually we're going to need some greenhouse gas removals to remove some emissions that are truly recalcitrant. [These] may be really difficult to remove but actually societally really important that we have those functions going on" (23:85). However, other participants recognised that such claims presume both that the activities defended are genuinely socially useful, and that the emissions involved are genuinely recalcitrant. In practice, these are not objective 'matters of fact', but dynamic, qualitative, social judgements open to reappraisal given technological change or changing mores and habits. In some groups such problems were recognised: "I ... fear that 'negative emissions' or 'greenhouse gas removal' is overused as a way of displacing too much recalcitrant emissions ... [it is] used too broadly as a term" (23:10). One participant suggested a need to be "really strict about your definition of recalcitrant or residual emissions" (23:86).

\section{'GGR itself is too limited, and the political climate unsupportive'}

The second broad argument offered against deterrence being a serious problem is that the limitations of GGR - especially its high cost - mean it is unlikely to substitute for emissions cuts, especially if the political environment remains hostile to serious climate action. Participants' views on this diverged widely. Where the workshops focused on one particular technology, such as direct air capture, such arguments were made more strongly. In the generic discussions, they rarely appeared, it perhaps being accepted that one or more GGRs might achieve scale at reasonable cost.

For some, GGR "is going to be 'a negligible rounding error' ... relative to other much more pressing issues. Populism and Trump and the economic transitions that we're going through are far greater mitigation deterrents than anything to do with GGRs" (22:109). Historic delay was often explained through an economic lens, as a result of inappropriate economic incentives. For instance: "I've been working with this for 20 years and I've been hearing the same thing all the time. There's no market. We can't do this" (21:95). Or, more generally stated: "the fossil fuel industry is massively subsidised because it's the only industry that's allowed to throw away its waste without paying" (19:6).

We also heard arguments that the scale of emissions reduction required makes displacement by limited techniques, such as enhanced weathering, "just totally unrealistic" (22:46). GGR was also sometimes seen as too expensive at scale to trigger deterrence: "GGR is not easy to do at the scales we're talking ... you're talking gigatonnes here ... the marginal cost curve is going to go exponentially high" (22:50). Others saw politics rather than revealed costs as the means to restrain exaggerated claims. For example "just messing around with soils ... wouldn't drown out other solutions because it wouldn't be ... a political[ly] acceptable response to a bigger challenge" (23:4). Whether economic or political, however, such arguments show a strong faith in the powers of reason, at odds with the current 'post-truth' context in which promises (or downright lies) can be much more powerful than might seem rational.

\section{'Someone would do something'}

It was also argued that if GGR delivery were failing, or were stimulating deterrence effects, someone would do something about it. For example: "there' $d$ be enough warnings and things, and science 
would be kind of stopping it from happening" (22:38). In a similar vein, the limitations of GGR would be exposed by rigorous assessment of the technologies by governments or investors: "people who control the money are going to look at it and go 'hell no! The numbers just don't work out'" (22:57). Or, more generally, exaggerated promises cannot persist: 'bullshit has a half-life' as one group memorably claimed. "So long as you can get away with the bullshit factor you will be able to get away with [it] ... But, the half-life [of] bullshit ... isn't 15 years, in the sense that by that point in time you've got enough analysis" (22:51). In another, public engagement was invoked as the factor that would dispel exaggeration: "I find it strange that we wouldn't have any [public] input at all especially seeing [corruption and inaction] unfold and other potential climate impacts" (23:100). This also implies an expectation that as climate impacts get more severe there will be a point after which delay and dissimulation would no longer be possible.

In two groups we heard assertions that previous fears about adaptation displacing or delaying mitigation action had not materialised, implying in context that GGR would also not have such an effect. Such claims emerged even as the groups consistently accepted the historic persistence of delay in delivering mitigation. Delay was understood as a natural consequence of a lack of political will, whereas neither the influence of promises about GGR or adaptation on political will, nor the novel temporal character of GGR promises, seemed easy to consider.

These objections are all 'rationalist' interpretations that largely disregard historical experience of persistent delay, continued active resistance by vested interests, and repeated technological promises of future action (McLaren and Markusson, 2020). To dismiss the possibility of serious deterrence through such arguments, one would have to assume that 'promises' can't substitute for action; that things that are small or expensive can't substitute (rhetorically and in policy) for big or cheaper ones; and that rational critique and assessment would necessarily be able to change political practice. All these assumptions fall into the rationalist register of discourse described above.

These arguments do indicate that not all participants accepted the premise of mitigation deterrence. However, the majority did. Political susceptibility was seen as commonplace: "any get-out-of-jail card for the harder bits of decarbonisation someone will grab hold of, whether it makes sense, whether it works, whether the science backs it up or not, even whether the economics backs it up or not" (22:41). Further, even those who expressed initial scepticism often came to accept or express the effects of mitigation deterrence as they worked through the scenarios.

\subsection{What can be done}

In this section we turn to the interventions that participants suggested to promote the delivery of GGR while minimising deterrence effects. The suggestions included reforming or regulating markets; treating GGR separately in policy and strategy; facing down the political power of incumbency especially in in fossil-based industry; and providing more transparency and accountability.

\section{Restrict and regulate markets}

Participants who did not acknowledge deterrence risks tended to support pricing and offsetting interventions. As one argued, "We need a price on $\mathrm{CO}_{2}$ emissions and ... we need to fund negative emissions. If we link those two needs with each other, which is quite obvious, then the polluters will have to pay for removing the $\mathrm{CO}_{2}$ from the atmosphere which is fair and this will solve the impossibility of funding negative emissions any other way." (21:18). These views seem rooted in a neoliberal social imaginary, in which markets are the primary policy tools, and the tradeability of any unit of $\mathrm{CO}_{2}$ for another via money is unquestioned. 
Such strong faith in markets was, however, a minority view. More typically, participants emphasized the weaknesses of markets, and the need for infrastructure and governance that markets won't provide. One argued: "paying for carbon dioxide removal should be done much as we think about paying for armouries or police or health services ... it's very hard to promote carbon negativity when you're trying to tax what we're trying to remove" (21:101). Some groups wanted to harness markets to promote efficiency, but called for tough regulation to structure markets in ways that could reduce the downsides of substitution and offsetting, such as a continually tightening cap driving total emissions lower.

Several participants advocated measures which establish value for carbon removal without relying on markets; for example, through a mandate imposed on fossil extractive industries to deliver incrementally larger removal targets for every tonne of $\mathrm{CO}_{2}$ generated by their activities and products (Haszeldine et al., 2018). If a carbon market remained: "That market has to value $\mathrm{CO}_{2}$ stored or removed by cancelling certificates" (25:86). Such mandates would internalise the cost trade-offs, but are not invulnerable to deterrence effects. Such a scheme might itself provide misplaced confidence in the future delivery of GGR, or legitimate a slower reduction in fossil use than otherwise possible.

Carbon pricing faced further criticism from those most concerned about mitigation deterrence. They argued that the attraction of delay cannot simply be overcome by putting a price on carbon, because of distributional effects and public opposition, as seen in the French 'gilets jaunes'. This wasn't to reject financial incentives outright, but to engage with some of the difficulties involved in making them effective and fair.

\section{Building an effective and separate GGR strategy}

There was fairly consistent support for a clear long-term GGR strategy: "a proper developed ... [GGR] strategy led by the state at some arm's length distance from technology developers and industry interests" (21:83). This would involve dedicated financial incentives for GGR rather than (or in addition to) a generic carbon price to stimulate experimentation and development. To help minimise substitution, it was argued, incentives should target removal, rather than utilisation.

\section{Facing down power and incumbency}

Most critically, participants argued that such a strategy needed actively to defuse the power of vested interests such as aviation and fossil energy, to prevent such sectors co-opting GGR as an offset, and redefining their activities as 'recalcitrant'. Vested interests should not be allowed to mobilise promises of GGR so as to resist action to reduce fossil fuel extraction. As one participant argued: "the thing that needs to happen is active deconstruction of that incumbency ... We need to actually actively close down these systems" (22:103).

Participants called for an international and intergenerational context for a GGR strategy, challenging not only the power of industry but also the power of nation states and the current generation. This would: "avoid getting locked into national level optimisations of GGR ... [that] miss out the need for some countries to do more than others" (22:94), and would require "those that initiate this process ... to have some commitment to the future rather than just the short term" (22:125). Some groups suggested that the attraction of delay, and the potential for temporal substitution of GGR for emissions reduction, could be reduced by developing a strategy with structured targets or carbon budgets for successive time-periods. 
Deflating exaggerated promises with enhanced accountability

A key way suggested to deflate GGR promises was to control the incentives for exaggeration by increasing accountability. Proposals for strengthened corporate and political accountability arose in many groups, and some also advocated new media accountability measures. Suggestions included both improved governance procedures and greater public involvement: "Things like better corporate governance to stop this secretive influencing going on, action towards better democratic governance and, in particular ... civil society resistance" (26:58). Public engagement, transparency, and accountability all came to the fore in different discussions: "you have to have some degree of transparency ... some degree of accountability for false, misleading or deceptive practices" (26:16). Arguing particularly for media accountability, one participant suggested: "mitigation deterrence is largely about belief. I think it's fundamentally a media issue. A media systems reform is actually fundamental to the dynamics of it" (24:93).

\section{Separation to minimise substitution}

Participants identified various dedicated interventions to minimise substitution of GGR for emissions reduction. More generally, they proposed reserving the limited and expensive capacity of GGR techniques for the restorative function of reducing atmospheric $\mathrm{CO}_{2}$, rather than permitting its use as an offset. Critical to managing such approaches is a principle of separation, proposed or endorsed in virtually all groups. For example: "This has to happen completely independent of all other climate [action]" to prevent a politician deciding that "we're doing enough now on this and slow[ing] down on all other climate mitigation" (23:5).

In several groups, participants - while broadly supportive - debated just how far to take separation. Some sought an entire separate policy framework, but for others dedicated accounting, designed with consideration of existing regimes to avoid overlaps and loopholes, would be enough. Many supported separate incentives, such as through: "a dedicated market ... not just a carbon price that applies to the whole ... economy that might not roll out any ... [expensive GGR] till the very end" (29:41). A key argument was to support new technology: "When you have a new technology that's by definition unreliable, being developed, you need a different form of support" (19:91). But one participant highlighted a risk if dedicated mechanisms continued to provide a higher financial incentive for removal than for emissions reduction because it could become profitable for a business to continue to emit more so it could then capture more: "It could be totally counterproductive" (21:74).

\section{Strengthening delivery}

We have already noted several interventions which could act to strengthen delivery of GGR. For instance, greater public engagement could reduce the risk of failure through public opposition. Measures to avoid fraudulent and exaggerated promises would limit the likelihood of public or policy backlashes that could also undermine deployment. Well-structured incentives and corporate accountability measures may help curtail rebounds from problems such as use of captured $\mathrm{CO}_{2}$ in enhanced oil recovery. Here we would note that there was a great deal of scepticism about other methods - besides targeted incentives - for funding GGR development. The critiques of simple carbon pricing and carbon market mechanisms were outlined above, but participants also rejected measures such as innovation prizes.

Effective monitoring and verification were frequently advocated. Along with the accountability benefits already described, these measures were often supported for very practical reasons. They would help identify problems or failures in removals or storage, help detect undesirable side effects or carbon rebound effects and enable corrective action to ensure delivery. For instance, there was a 
call for: "a huge amount of robust monitoring ... [of GGR] operations or the effects of those operations or the side effects of those operations, [and] ... the governance systems" (22:95).

In some groups, participants also took the view that failure cannot always be prevented - so redundancy, across a portfolio of GGR would be important. Acknowledging the risks of failure as a result of future leakage, especially with techniques such as soil carbon restoration which require ongoing maintenance of carbon stores, several groups saw particular value in identifying and incentivising co-benefits beyond climatic effects (Mayrhofer and Gupta, 2016). Some argued that such an approach would not only sustain storage, but strengthen stakeholder support and delivery more broadly.

\section{Beyond technical interventions}

While some few participants remained sceptical of the underlying need for interventions to minimise deterrence, most considered the proposed interventions valuable anyway as a means of strengthening delivery of GGR. On the other hand, those most concerned about problems of delay and deterrence tended to argue for more systemic change, rather than seeking to design new markets or regulatory systems. For example: "we actually need some sort of public conversation on what it means to be human at the moment in relation to the planet" (24:51).

\section{Discussion}

Our findings suggest that there are good reasons to worry about mitigation deterrence, and that concerns about deterrence effects are widely shared amongst climate/GGR stakeholders. However, for many stakeholders, the urgency of climate action, and the failure so far to achieve adequate mitigation, create a context in which delivering GGR is seen as more important than any possible interaction effects. They express concerns that worrying about mitigation deterrence might unduly constrain or hamper action to research or deliver GGR. However, when exposed to unsettling scenarios and engaged with the topic, most stakeholders recognised that aspects of the dominant social imaginary and the political economy of climate change (such as presumptions about sciencebased policy, expectations regarding innovation, and faith in markets) act to downplay and conceal important drivers of mitigation deterrence (the attraction of delay, vested interests in deploying GGR as offsets, etc.). As a result, stakeholders (even those most sceptical of the extent of the problem of mitigation deterrence) overwhelmingly supported interventions that would help minimise the impacts of deterrence - notably measures to separate accounting and incentives for GGR from those for emissions reduction - within a broad climate strategy that includes positive support for GGR.

The workshops were not designed to reach consensus. Yet many participants became more open to considering deterrence problems, and discussing the ambiguities and tensions involved, as they moved beyond the 'rationalist' register in the course of the discussions (as reported in sections 3.2 and 3.3 above). In addition, we argue that the presence of rationalist arguments against deterrence in the workshops is itself an indicator of the prevalence of the problem. Conventional approaches to climate policy draw heavily on science and rationalism. But 'rationalist' rejections of concerns over deterrence such as those noted in Section 3.2 risk increasing the spaces within which deterrence effects can occur. Reliance on calculative integrated assessment modelling with its inherent preference for future speculative technology over apparently costly near-term mitigation (see also McLaren 2020) is one such risk. Another arises in the way that a rationalist register interprets the 'post-truth' phenomenon of 'fake news' being propagated by vested commercial and political interests as merely 'irrational' exceptions to what is otherwise understood as fundamentally rational 
political discourse. As we saw in section 3.2, responses located in a rationalist register tend to downplay the political and cultural significance of such processes and thus unwittingly risk enabling deterrence. This implies that it is critical for policy not simply to declare the possibility of mitigation deterrence 'irrational', but to acknowledge and engage with it, and with its underlying - and evidently manifest - cultural, political and social drivers.

\section{Recognising the problem}

Our research indicates the importance of naming and making explicit the problem of mitigation deterrence. As seen above, even some engaged experts and stakeholders experience persistent obstacles to talking about the issue. From this perspective, the workshop accounts also offer insights into the subjective experience of living with the pressures and tensions that underlie mitigation deterrence. It appeared easier for many stakeholders to think in terms of the kinds of interaction effects between options (such as price and resource competition) that models are relatively good at handling, whereas the kinds of cultural and political economy effects revealed here are less intuitive or familiar. For example, initial efforts to rebut deterrence problems often reflected an individualist economic approach presenting substitution (of GGR for mitigation, through markets or offsetting), as rational, unproblematic, and largely disconnected from the realm of exaggerated promises, failure risks, unintended emergent 'common-senses' and side-effects that became clear later in the discussions. Such views of substitution perhaps represent a misplaced assumption of fungibility between emissions reductions and carbon removals, which in turn reflects the dominant neoliberal social imaginary (Groves, 2014; Markusson et al., 2018). They also illustrate the shortcomings of the conventional 'moral hazard' framing, in which the risk of mitigation deterrence is understood mainly in terms of individually and rationally assessed risks and benefits (McLaren 2016; Markusson et al 2018).

Moreover, thinking about mitigation deterrence from GGR can be painful. ${ }^{6}$ For participants concerned about climate change and aware of the magnitude of the problem, there is a tension inherent in considering the possibility that pursuing GGR - seen by most as an essential contribution to managing climate change - might at the same time risk exacerbating the problem. Contemplating this tension can be emotionally difficult. We suspect it was therefore important for many participants first to express support for and defend GGR, before being comfortable in acknowledging the risks of mitigation deterrence and exploring such unintended consequences, especially amidst groups of relative strangers. As the sessions moved into discussion of mechanisms and particularly interventions, the opportunity to offer responses that could both help deliver GGR and minimise deterrence generated more wholehearted acknowledgement and analysis of the deterrence problem. And our scenario methodology functioned effectively to facilitate collective engagement with mitigation deterrence, as a possible challenge to everyone, irrespective of politics. We would therefore recommend such deliberation as a key part of policy development (Flyvbjerg et al., 2012), as a tool to enable policy-makers to recognise and engage with the problem.

\section{Understanding the mechanisms}

Acknowledging the problem of deterrence is a first key step in addressing it. But the workshops also help us understand the mechanisms of deterrence. While often not formal experts in such considerations, and in some cases uncomfortable with them (as noted above), the participants nonetheless informatively explored underlying cultural, economic and political drivers - the construction of promises, the incentives for exaggeration, and the interests involved in constructing and communicating promises (including modellers, media, and commercial actors). In their

\footnotetext{
${ }^{6}$ This aspect of the workshops is discussed further in [redacted for anonymity] (forthcoming).
} 
discussions, we saw reflected the social imaginaries that structure contemporary societies imaginaries of rational economics, scientific advice, market-based policy measures, administrative policy development, and commodification of carbon (cf Carton, 2020; Carton et al., 2021; Lohmann, 2005; Groves, 2014). We also saw critiques of those imaginaries in contributions that highlighted the ways in which businesses, politicians and others are predictably attracted to delay, and how they use language to exaggerate and mislead to such ends.

GGR promises are just one example of the 'attraction of delay' in a setting in which there are many incentives for politicians, businesses and publics to promote or accept delay. We do not suggest that our deliberations revealed something exclusive to GGR. But to attribute delay and deterrence to all sorts of other factors, but not GGR, as some participants did, would demand explanation of why excessive expectations generated by GGR promises would be uniquely counteracted by rationalist approaches. In the discussions, such participants instead reinforced arguments as to why GGRs themselves might not materialise in practice (cf Waller et al., 2020; Thoni et al., 2020), suggesting that GGR promises should be treated sceptically, and implicitly making a case for protections against mitigation deterrence, rather than a case to dismiss it. Moreover, unlike many other promises, exaggeration about GGR cannot be rationally dispelled in 'real-time', because GGR acts as a 'timemachine' in climate policy, being able to promise future reversal of current and past emissions, and thus becoming a 'temporal' socio-ecological fix (cf Ekers and Prudham, 2017; Sapinski, 2016).

More generally, in the processes described by some participants we see clear echoes of Stephen Gardiner's (2011) concern about 'moral corruption' in climate policy. Gardiner sees a serious moral failing when those both responsible for most historic emissions, and with the capacity to take action, delay action to address climate change. He suggests that moral corruption might be at play when such actors self-justify prevarication, on the basis of claims of high cost or practical difficulty, but with outcomes that maintain their comfort and lifestyles, at the risk of the lives and wellbeing of those least responsible for climate change. What seems logical can still be a moral failing, and in such circumstances we may need help to understand our motivations for delay.

Any intervention that provides a 'semblance of action', or a basis for the self-delusion that delay can be justified, might be deployed as a prevarication. But reliance on GGR promises in such circumstances is more problematic, because it extends the potential period of delay into an era of emissions overshoot. Whether technological (such as nuclear power) or behavioural (such as lifestyle change), no previous promise, however exaggerated, could offer to reverse past emissions. In recent years, offsetting has been a central mechanism for prevarication despite similar concerns about its effectiveness (Watt, 2021). But now that carbon budgets are being exhausted, the scientific and political credibility of offsetting action to other countries or other sectors is declining. We appear to need not merely techno-fixes but 'retro-techno-fixes' - technological promises which can "change the past" (Anderson, 2015), effectively acting as time machines. GGR offers such a promise to actors facing real material incentives to delay action and transfer the costs to others. Even as the spatial carbon frontier seems to be closing, the promises of GGR are extending a temporal carbon frontier.

\section{Promoting solutions}

As outlined in section 3, participants offered a wide range of potential interventions. These interventions offer opportunities to minimise deterrence that can be integrated with ways to stimulate delivery of GGR, but only as long as the problem is actually recognised, not just dismissed. Indeed, designing and framing interventions in this way is more likely to ensure wide support (Cox et al., 2020). Active measures to control deterrence such as improved monitoring and verification 
would not only make fraudulent offsetting more difficult, but would also help validate GGR for the targeting of incentives. In such ways anti-deterrence measures would likely lead to more GGR delivery as well as to more conventional mitigation.

\section{Witch-hunting, framing and group composition}

Before concluding, we want briefly to consider some possible criticisms. Did our methods possibly create or construct fears of mitigation deterrence in the participants through the framings used? It is true that all the scenarios involved some forms of deterrence and that the discussions focused on this issue. However, our participants were given ample opportunity to challenge both the scenarios and the mechanisms suggested. Some did so, though typically briefly, while others appeared to be more comfortable discussing the problem in this environment.

In reviewing our methods and findings the team also embarked on some reflexive questioning. In particular, we asked whether our reactions to those who sought to downplay or rebut deterrence effects constituted 'witch-hunting'. Were we seeing (concealed) deterrence effects in those who denied being affected, while welcoming the admissions of those who agreed that there might be a problem - and thus offering interpretations that were both unfalsifiable and unfair? While we did conclude that denying the risk of deterrence might enable it, we do not claim that our participants demonstrated that personally, and have been careful to consider other explanations as to why participants might have questioned deterrence.

Finally, were our groups particularly susceptible to worries about deterrence because of their composition? We assembled groups that were broadly representative of GGR stakeholders, and, if anything, we suspect the opposite: that the group composition may have increased scepticism about deterrence. Our groups were predominantly male, northern, white and educated (comparable to the WEIRD - white, educated, industrialised, rich and democratic - bias noted in psychology (Henrich et al., 2010)), likely therefore to share both the rationalist world view highlighted earlier, and the privilege that tends to increase susceptibility to moral corruption. The variation between our groups in gender balance, and inclusion of young, student voices was not great enough to draw firm conclusions about the impacts of group composition on the content and tenor of the discussions. However, we did see an apparent tendency for groups with more youthful and fewer 'expert' participants to experience more wide-ranging conversations. And certain arguments were made exclusively by particular demographics. For example unequivocal support for $\mathrm{CO}_{2}$ pricing was voiced only by older, white men, perhaps because they were less likely to question social and political orthodoxies (See section 3.3). In our analysis, we have sought to surface the imaginaries reflected and voiced by participants, and this leads us to suspect that more diversity would probably have provided more and deeper challenges to the dominant, rationalist, economistic social imaginary unconsciously shared by many of our participants.

\section{Conclusions}

Collective deliberation on GGR enables stakeholders to recognise risks of mitigation deterrence which arise from emerging and often exaggerated promises - conveyed through models, media and political debate - regarding the future contribution of GGR to addressing climate change. In this respect, GGR discourse can be understood as exemplary of how technological promises are enrolled in cultural, economic and political processes to enable prevarication and delay where significant change that is not purely technological and instrumental would threaten the dominant social order. In other words, through a combination of 'objectivist rationalisations', taken-for granted elements of capitalist hegemony, and isolated technological imaginaries, evaluations of GGR on a 'rationalist' 
register not only overestimate feasibility (Waller et al., 2020; Thoni et al., 2020) but also underpin multiple dynamics of delay, 'enabled' - using Stoddard et al's (2021) term - by politically naïve scientific endorsement of ideological constructs such as commodification and offsetting. Such practices also enable hegemonic economic interests to mobilise GGR promises as (spatio-)temporal fixes as a means of avoiding politically transformative change (Markusson et al., forthcoming).

Yet, in collective deliberation, stakeholders also tended to converge on potential measures to counter these effects and to strengthen the delivery of GGR in practice. These measures include the formal separation of GGR incentives, targets and accounting from emissions reduction policy; greater emphasis on interventions (such as enhanced liability and accountability) to counteract or dismantle the power of incumbent vested interests, and to deflate the power of exaggerated promises; provision of strong incentives for GGR beyond carbon prices and carbon markets, including incentives based on co-benefits; and tough standards of monitoring, reporting and verification.

The challenges we found in generating discussion of deterrence problems illustrate the value of having an analytic framework and a language in which such cultural, political and economic effects can be taken seriously and considered reflexively, even by those not self-consciously adept or comfortable in such considerations. When discussion remained on a rationalist register, the full extent of the risks was not revealed. It was only in the depths of our workshop discussions that the distinctive temporal dimensions of these promises, and the ways that promises themselves can act to reconstruct their subjects (for example, the way GGR enables recalcitrance to be redefined), came to the fore. But this happened in the workshops regardless of the composition of the group and their explicit professional orientation to such broader social issues, as participants brought their broader experience as sophisticated social, political and cultural agents, not just their specific knowledge and cognitive expertise, to bear collectively on the discussion. These results speak positively of the potential for broad public engagement in such discussions leading to insights and learning for those involved, moving beyond a default and 'common-sense' rationalist register.

Our findings may also be of more general use in the climate debate. The perspective applied here suggests the need for deeper engagement with the political-economic and cultural dimensions of climate change. If we can understand and counter the reasons for mitigation deterrence from GGR, this may help us better understand and counter the causes of resistance to mitigation action more generally. And in the reasons for 'rejection' of this problem (and by whom, using what narratives), there are insights as to why reasonable people get caught up in practices of policy advice or other interventions that enable or cause continued delay. This is critical in the current 'climate emergency' discourse. How is it that politicians can acknowledge a climate emergency, yet also grant permissions for new coalmines, pipelines or airport expansions, and bail out existing bankrupt airlines? (Willis, 2019). Our analysis of the way technological promises are mobilised in service of the dominant social imaginary offers a way to understand - and perhaps begin to overcome - the striking disjunctures between declarations of emergency and political procrastination. 


\section{Author contributions:}

DM: Conceptualization; data curation; formal analysis; methodology; writing - original draft

RW: Methodology; workshop facilitation; contribution to original writing

BS: Formal analysis; contribution to methodology; writing - review \& editing

DT: Formal analysis; contribution to methodology; writing - review \& editing

NM: Conceptualization; formal analysis; contribution to original writing and methodology

Acknowledgements: The authors would like to thank all the workshop participants for their constructive contributions, and our colleague Andrew Jarvis for his valuable feedback as the paper developed.

Funding statement: The manuscript was written with support from grant NE/P019838/1 from the programme Greenhouse Gas Removal from the Atmosphere, funded by NERC, EPSRC, ESRC, BEIS, Met Office \& STFC in the UK.

Declaration of interests: The authors declare that they have no known competing financial interests or personal relationships that could have appeared to influence the work reported in this paper.

Research ethics: This study was reviewed and approved by Lancaster University Faculty of Science and Technology Research Ethics Committee. All subjects gave written informed consent in accordance with the Declaration of Helsinki.

Data availability: In line with the consent provided by participants, to protect personal identities, raw data cannot be made available. An anonymised subset of the transcribed material has been provided as supplementary information (link).

\section{References}

Anderson K (2015) Duality in Climate Science. Nature Geoscience 8(Dec): 898-900.

Anderson K and Peters G (2016) The trouble with negative emissions. Science 354(6309): 182.

Beck S and Mahony M (2018) The politics of anticipation: the IPCC and the negative emissions technologies experience. Global Sustainability 1: e8.

Bellamy R and Lezaun J (2017) Crafting a public for geoengineering. Public Understanding of Science 26(4): 402-417.

Bellamy R, Lezaun J and Palmer J (2019) Perceptions of bioenergy with carbon capture and storage in different policy scenarios. Nature Communications 10(1): 743.

Burchardt T (2013) Deliberative research as a tool to make value judgements. Qualitative Research 14(3): 353-370.

Carton W (2019) "Fixing" Climate Change by Mortgaging the Future: Negative Emissions, Spatiotemporal Fixes, and the Political Economy of Delay. Antipode 51(3): 750-769.

Carton W (2020) Carbon unicorns and fossil futures. In: Buck HJ, Sapinski JP and Malm A (eds) Has It Come to This?: The Promises and Perils of Geoengineering on the Brink. Rutgers University Press.

Carton W, Lund JF and Dooley K (2021) Undoing Equivalence: Rethinking Carbon Accounting for Just Carbon Removal. Frontiers in Climate 3(30).

Chilvers J and Kearnes M (2019) Remaking Participation in Science and Democracy. Science, Technology, \& Human Values. DOI: 10.1177/0162243919850885. 0162243919850885.

Cox E, Spence E and Pidgeon N (2020) Public perceptions of carbon dioxide removal in the United States and the United Kingdom. Nature Climate Change 10(8): 744-749.

Douglas M (1970) Natural Symbols: Explorations in Cosmology New York: Pantheon Books. 
Ekers M and Prudham S (2017) The Metabolism of Socioecological Fixes: Capital Switching, Spatial Fixes, and the Production of Nature. Annals of the American Association of Geographers 107(6): 1370-1388.

Flyvbjerg B, Landman T and Schram S (2012) Real social science: Applied phronesis. Cambridge: Cambridge University Press.

Fuss S, Canadell JG, Peters GP, et al. (2014) Betting on negative emissions. Nature Climate Change 4: 850.

Gardiner SM (2011) A Perfect Moral Storm: The Ethical Tragedy of Climate Change. Oxford: Oxford University Press.

Groves C (2014) Care, Uncertainty and Intergenerational Ethics. Palgrave Macmillan.

Harvey D (2003) The New Imperialism. Oxford University Press.

Haszeldine RS, Flude S, Johnson G, et al. (2018) Negative emissions technologies and carbon capture and storage to achieve the Paris Agreement commitments. Philosophical Transactions of the Royal Society A: Mathematical, Physical and Engineering Sciences 376(2119).

Henrich J, Heine SJ and Norenzayan A (2010) The weirdest people in the world? Behavioral and Brain Sciences 33(2-3): 61-83.

Jasanoff S (2007) Designs on Nature: Science and Democracy in Europe and the United States.

Jasanoff S (2015) Future Imperfect: Science, Technology, and the Imaginations of Modernity. In: Jasanoff S and Kim S-H (eds) Dreamscapes of Modernity: Sociotechnical Imaginaries and the Fabrication of Power. University of Chicago Press, Chicago, IL.

Jessop B (2006) Spatial Fixes, Temporal Fixes and Spatio- Temporal Fixes. In: Castree N and Gregory D (eds) David Harvey: A Critical Reader. Oxford: Blackwell, pp.142-146.

Jessop B (2009) Cultural Political Economy and Critical Policy Studies'. Critical Policy Studies 3: 336356.

Lohmann L (2005) Marketing and making carbon dumps: Commodification, calculation and counterfactuals in climate change mitigation. Science as Culture 14(3): 203-235.

Luderer G, Vrontisi Z, Bertram C, et al. (2018) Residual fossil CO2 emissions in $1.5-2{ }^{\circ} \mathrm{C}$ pathways. Nature Climate Change 8(7): 626-633.

Markusson N, McLaren D, Szerszynski B, et al. (forthcoming) Life in the hole: Practices and emotions in the cultural political economy of mitigation deterrence. European Journal of Futures Research.

Markusson N, McLaren D and Tyfield D (2018) Towards a cultural political economy of mitigation deterrence by negative emissions technologies (NETs). Global Sustainability 1: e10.

Mayrhofer JP and Gupta J (2016) The science and politics of co-benefits in climate policy. Environmental Science \& Policy 57: 22-30.

McLaren D (2016) Mitigation Deterrence and the 'Moral Hazard' in Solar Radiation Management. Earth's Future 4(12): 596-602.

McLaren D (2020) Quantifying the Potential Scale of Mitigation Deterrence from Greenhouse Gas Removal Techniques. Climatic Change 162: 2411-2428.

McLaren D and Markusson N (2020) The co-evolution of technological promises, modelling, policies and climate change targets. Nature Climate Change. DOI: 10.1038/s41558-020-0740-1.

Moreno C, Speich Chassé D and Fuhr L (2015) Carbon Metrics. Global abstractions and epistemological epistemicide. Berlin: Heinrich Böll Stiftung,.

Nardin T (2015) Rationality in politics and its limits. Global Discourse 5(2): 177-190.

Newell P and Paterson M (2010) Climate capitalism: global warming and the transformation of the global economy. Cambridge University Press.

Peters GP and Geden O (2017) Catalysing a political shift from low to negative carbon. Nature Climate Change 7: 619.

Rogelj J, Huppmann D, Krey V, et al. (2019) A new scenario logic for the Paris Agreement long-term temperature goal. Nature 573(7774): 357-363. 
Rogelj J, Popp A, Calvin KV, et al. (2018) Scenarios towards limiting global mean temperature increase below $1.5^{\circ} \mathrm{C}$. Nature Climate Change 8(4): 325-332.

Sapinski JP (2016) Managing the carbon rift: Social metabolism, geoengineering and climate capitalism. In: American Sociological Association, Seattle.

Stoddard I, Anderson K, Capstick S, et al. (2021) Three Decades of Climate Mitigation: Why Haven't We Bent the Global Emissions Curve? Annual Review of Environment and Resources 46(1): null.

Sum N-L and Jessop B (2013) Towards a cultural political economy: putting culture in its place in political economy. Edward Elgar.

Taylor C (2003) Modern Social Imaginaries. Duke University Press, Durham NC.

Thoni T, Beck S, Borchers M, et al. (2020) Deployment of Negative Emissions Technologies at the National Level: A Need for Holistic Feasibility Assessments. Frontiers in Climate 2(12).

Tyfield D (2020) Phronesis (and its potentially central contribution to mobilities research in the 21st century). In: Buscher M, Freudendal-Pedersen M, Kesselring S, et al. (eds) Handbook on Methods and Applications for Mobilities Research. Cheltenham: Edward Elgar.

Waller L, Rayner T, Chilvers J, et al. (2020) Contested framings of greenhouse gas removal and its feasibility: Social and political dimensions. WIREs Climate Change 11(4): e649.

Watt R (2021) The fantasy of carbon offsetting. Environmental Politics. DOI: 10.1080/09644016.2021.1877063. 1-20.

Wilkinson A, Kupers R and Mangalagiu D (2013) How plausibility-based scenario practices are grappling with complexity to appreciate and address 21st century challenges. Technological Forecasting and Social Change 80(4): 699-710.

Willis R (2019) The role of national politicians in global climate governance. Environment and Planning E: Nature and Space. DOI: 10.1177/2514848619887464. 